Enferm Bras 2020;19(6):456-8

https://doi.org/10.33233/eb.v19i6.4557

\title{
EDITORIAL \\ Empreendedorismo inovador do enfermeiro brasileiro: será preciso reinventar-se a partir de 2021!?
}

Zaida Aurora Sperli Geraldes Soler, D.Sc. ${ }^{*}$, Marli de Carvalho Jericó, D.Sc. ${ }^{*}$, Fabricio Renato Teixeira Valença***

*Obstetriz, Enfermeira, Livre-Docente, docente e orientadora da graduação e pós-graduação lato sensu e stricto sensu da Faculdade de Medicina de São José do Rio Preto (FAMERP) SP, **Enfermeira, Doutora da graduação e pós-graduação lato sensu e stricto sensu da Faculdade de Medicina de São José do Rio Preto (FAMERP)/SP, ${ }^{* \star * E n f e r m e i r o, ~ g r a d u a d o ~ e m ~ E n f e r m a g e m ~}$ da Faculdade de Medicina de São José do Rio Preto (FAMERP)/SP

Zaida Aurora Sperli Geraldes Soler: zaidaaurora@gmail.com

Marli de Carvalho Jericó: marli@famerp.br

Fabricio Renato Teixeira Valença: fabricio.valenca1@gmail.com

Por definição, empreendedorismo significa assumir riscos no planejamento, implementação, coordenação e gestão de projetos, serviços e negócios. Os empreendedores estão entre os profissionais e ocupacionais que por interesse, necessidade e oportunidade buscam atuar de forma liberal ou autônoma, com determinadas características de personalidade, como: capacidade de gestão; autocontrole; autoavaliação, de forma a estabelecer objetivos, planos e metas para otimizar ações no trabalho e superar obstáculos [1].

O conceito de inovação, bastante usado no meio empresarial, aproxima-se do entendimento da capacidade de "criar", "de certa forma "inventar" novidades, sejam ideias, estratégias, ferramentas, tecnologias, processos, caminhos e serviços. Em nossa opinião, o vivenciado em 2020, ao menos nos países democráticos, vai exigir uma adaptação do mundo do trabalho e no empreendedorismo de negócios, como forma de entrar ou continuar no mercado empresarial, inovando para se moldar às mudanças sociais e econômicas, reinventando-se para recriar, refazer ou renovar o já instituído.

Atualmente o empreendedorismo tem ficado em destaque como um caminho inovador na enfermagem brasileira, sendo o enfermeiro preparado e eticamente e legalmente qualificado para ter uma compreensão mais ampla das necessidades humanas em diferentes dimensões; para explorar novos espaços e por ser uma carreira do futuro, o cuidar. Assim, aqueles que empreendem buscam alcançar, além do retorno financeiro, prestar uma assistência qualificada, responsável, embasada em evidências científicas, técnicas corretas e respeito aos preceitos éticos e legais [2].

Além das competências múltiplas aprendidas na formação e a experiência que levará a maior domínio do processo de cuidar, vários pontos positivos são apontados pelos profissionais de enfermagem empreendedores, como ser dono de seu próprio negócio sem subordinação hierárquica, flexibilidade de horário com eliminação do cartão de ponto, independência financeira e libertação dos salários tabelados. Para desenvolver e incorporar o comportamento empreendedor algumas atitudes, ditas soft skills, são destacadas, como exercitar a criatividade, capacidade de implementação, senso de independência, perseverança, otimismo e disposição em assumir riscos. Também, há a necessidade do conhecimento técnico do empreendedorismo, conhecido como hard skill, em como desenvolver o plano de negócios, gerenciar o negócio, captar recursos e identificar e avaliar a oportunidade [3].

Como docentes, temos observado que muitos acadêmicos de enfermagem estão ávidos por conhecer o empreendedorismo na enfermagem e as várias formas de atuação do empreendedor enfermeiro, fascinados pela possibilidade do mercado de trabalho autônomo. Em nosso meio, há disciplinas que abordam a temática, muitos alunos participam de ligas de gestão em saúde, de networks, principalmente com uso das redes sociais e vários alunos desenvolvem seu trabalho de conclusão de curso (TCC) nesse enfoque. É visível no comportamento da nova geração de acadêmicos de enfermagem jovens a fuga de modelos tradicionais de atuação 
profissional, estão mais ligados no tecnológico e na busca por outros modos de vida pessoal e profissional [1].

Com vistas a regulamentar a atuação de enfermeiros empreendedores, a Resolução COFEN $n^{\circ}$ 0568/2018 respalda o enfermeiro brasileiro na atuação como profissional liberal no marketing empresarial. Além de incentivar graduandos de enfermagem no foco do empreendedorismo, tal resolução incentiva enfermeiros interessados a potencializar, melhorar e fortalecer ações como empreendedor, como opção de crescimento, autonomia, prestígio e reconhecimento profissional [4].

O ano de 2020 sempre ficará em nossa memória e particularmente da enfermagem. De início, traz reminiscência sobre o bicentenário de Florence Nightingale, precursora da enfermagem moderna, profissional e uma das figuras femininas mais importantes na história. Entre seu legado, que transcende a diferentes áreas de conhecimento, está 0 empreendedorismo social que desenvolveu, com atitude visionária, abrangência social humanitária e potencial transformador de percursos e realidades ainda presentes na contemporaneidade [5].

Além do bicentenário de Florence, festejamos em 2020 a finalização da campanha Nursing Now, que mostrou a relevância da enfermagem na agenda global. A Organização Mundial da Saúde (OMS), definiu o ano de 2020 como o Ano Internacional da Enfermagem e Obstetrícia, reconhecendo o trabalho realizado por enfermeiros e parteiros em todo o mundo e a importância desses profissionais para atingir a meta de cobertura universal da saúde em 2030. Foi nesse movimento na enfermagem mundial que os continentes, um após o outro, foram surpreendidos pela pandemia causada pelo novo coronavírus (SARS-CoV-2), chamada de COVID-19, considerada como um dos mais importantes problemas mundiais de saúde pública dos últimos 100 anos. Como consequência, houve necessidade de o enfermeiro reinventar-se em todos os campos de atuação, para estabelecer novos mecanismos de proteção da saúde de quem é cuidado e daquele que cuida [6].

Neste fatídico ano de 2020, que se acaba sem sinais de finalização de suas ocorrências, para se poder agir nas consequências, os meios de comunicação de todo o mundo têm apresentado diuturnamente as questões de saúde/doença, políticas, econômicas, sociais e profissionais relacionadas à COVID-19. Em estudo brasileiro recente, apresentou-se os apelos da enfermagem em mídias sociais, categorizados em \#fiqueemcasa, \#cadêmeuEPI, \#agorasomosheróis, \#nadadenovonofront, que revelam novos desafios profissionais, em busca de alicerçar políticas de melhoria das condições laborais para a enfermagem brasileira; reconhecer e valorizar os profissionais que não se afastam do cuidado das pessoas [7].

Discute-se a ascensão do empreendedorismo de negócios na enfermagem brasileira desde o início dos anos 2000, fato associado à insatisfação no trabalho, necessidade de melhores ganhos ou mesmo a busca de novas perspectivas profissionais. Para tanto destacavase a necessidade de formação adequada no desenvolvimento do empreendedorismo de enfermeiros, condizentes com demandas sociais e necessidades do mercado de trabalho. Isso pode provocar mudanças efetivas na vida pessoal e profissional e estimular outros profissionais, além de contribuir o reconhecimento, valorização, prestígio e melhor imagem da profissão [8]. Agora temos mais um desafio pela frente, no foco do empreendedorismo empresarial da enfermagem, em tempos de pandemia.

Apesar de pouca valorização social, a enfermagem sempre foi uma profissão com grande possibilidade de vaga de trabalho, pela alta demanda por profissionais e abrangência do mercado de trabalho corporativo de saúde pública e privada. Agora em 2020, quando vivenciando em tempo real a pandemia COVID-19, assistindo situações de desemprego num contexto permeado de grandes desafios/contradições/caos de toda ordem. Tal crise, na percepção de perfis, espíritos e atitude mental empreendedoras constitui-se em momento fértil de oportunidade nesse mundo de complexidade do cuidado em saúde abrindo, assim, novos espaços para um trabalho inovador que poderá transformar a atenção em saúde no Brasil [1,7].

Em todas as situações de guerras e calamidades, a enfermagem está presente como a profissão com maior atuação de cuidado direto. As tristezas trazidas por essa pandemia mostraram muitas vezes os profissionais de enfermagem que nunca se afastaram do cuidado aos doentes mais graves, homenageados com palmas em janelas e chamados de heróis. A partir de 2021 teremos muitos os desafios no ensino e exercício da enfermagem brasileira. Teremos que nos reinventar para revelar caminhos para desenvolver novas competências profissionais que facilitem a inserção em um novo mundo de trabalho. Urge realizar estudos e pesquisas que mostrem alternativas em relação ao trabalho corporativo. É possível que empreender, com 
profundidade de embasamento técnico-científico, inovação e criatividade, seja uma das opções viáveis para maior conhecimento, reconhecimento e valorização da enfermagem como profissão.

\section{Referências}

1. Valença FRT, Jericó MC, Gouveia JL, Soler ZASG, Dal Bem LW. Perfil de Empreendedores da Enfermagem em instituições de longa permanência para idosos. Enferm Bras 2020;19(5):411-22. https://doi.org/10.33233/eb.v19i5.4469

2. Carneiro AL, Pereira I, Viana MRP. Empreendedorismo: um caminho inovador na Enfermagem. RSD 2020;9(9):e868997994. https://doi.org/10.33448/rsd-v9i9.7994

3. Colichi RMB, Lima SGSe, Bonini ABB, Lima SAM. Empreendedorismo de negócios e Enfermagem: revisão integrativa. Rev Bras Enferm 2019;72(supl1):321-30. https://doi.org/10.1590/0034-7167-2018-0498

4. Fonseca GKL, Araújo CL, Olivindo DDF. Empreendedorismo de enfermagem: motivações e possibilidades para empreendedores de enfermagem. RSD 2020;9(7):e597974442. https://doi.org/10.33448/rsd-v9i7.4442

5. Backes DS, Toson Junior M, Dal Bem LW, Erdmann AL. Contribuições de Florence Nightingale como empreendedora social: da enfermagem moderna à contemporânea. Rev Bras Enferm 2020;73(Suppl5):e20200064. https://doi.org/10.1590/0034-71672020-0064

6. Forte ECN, Pires DEP. Os apelos da enfermagem nos meios de comunicação em tempos de coronavirus. Rev Bras Enferm 2020;73(Suppl 2):e20200225. https://doi.org/10.1590/0034-7167-2020-0225

7. Falcão VTFL. Os desafios da Enfermagem no Enfrentamento a COVID-19. Rev Enferm Digit Cuid Promoção Saúde 2020;5(1):1-2. https://doi.org/10.5935/2446-5682.20200001

8. Andrade AC, Dal Bem LW, Sanna MC. Empreendedorismo na Enfermagem: panorama das empresas no Estado de São Paulo. Rev Bras Enferm 2015;68(1):40-4. https://doi.org/10.1590/0034-7167.2015680106p 